Hydrol. Earth Syst. Sci. Discuss., doi:10.5194/hess-2016-536, 2016

\title{
Climate change and uncertainty in high-resolution rainfall extremes
}

\author{
Bahareh Kianfar ${ }^{1}$, Simone Fatichi ${ }^{1}$, Athanasios Paschalis ${ }^{2}$, Max Maurer ${ }^{1,3}$, and Peter Molnar ${ }^{1}$ \\ ${ }^{1}$ Institute of Environmental Engineering, ETH Zurich, Zurich, Switzerland \\ ${ }^{2}$ Faculty of Engineering and the Environment, University of Southampton, Southampton, United Kingdom \\ ${ }^{3}$ Eawag, Swiss Federal Institute of Aquatic Science and Technology, Duebendorf, Switzerland \\ Correspondence to: Peter Molnar (molnar@ifu.baug.ethz.ch)
}

\begin{abstract}
.
A methodology to analyze the impact of climate change on rainfall extremes with a high temporal resolution is presented. It is based on a rainfall stochastic simulator which consists of a point process model for the daily scale (Neymann-Scott Rectangular Pulse Model) and a nested disaggregation scheme for the 10-min rainfall scale (Multiplicative Random Cascade Model). Climate change signals are included as Factors of Change applied to key statistics (first-third order moments, correlation and intermittency) as simulated with ten GCM-RCM model chains of the ENSEMBLES Project. The stochastic simulator was calibrated with data from 22 meteorological stations in Switzerland, and used to analyze rainfall extremes from 30-yr long realizations for the current climate and two future climate periods (mid-Century and end-of-Century). The stochastic simulator reproduces first and higher-order statistics of precipitation very well for temporal scales from 10-min to 24-hr, including annual maxima for a range of return periods relevant for urban hydrology. The internal climate variability (stochasticity) in rainfall extremes can be directly quantified using simulations, and is very high. Despite the imposed climate change signals, the distributions of annual maxima for the current and future climates largely overlap in most climate model chains. There are relatively few cases where the mean future extremes lie outside of the 10-90\% uncertainty bounds of the current climate, and in fact both increases and decreases are found in simulations. The rainfall stochastic simulator can be improved in the future by including the relation between extreme rainfall intensity and air temperature in the parametrisation. We conclude that the climate change signal generated by climate models has a low signal-to-noise ratio in rainfall extremes at high resolutions at the station level and predictions of change are therefore highly uncertain. At the same time, accounting for current climate variability in rainfall extremes for urban hydrologic design is vital because it may already cover a large part of the uncertainty connected with expected climate change in the future.
\end{abstract}

\section{Introduction}

The intensification of precipitation extremes under a future warmer climate (e.g., Berg et al., 2013; Westra et al., 2014; O'Gorman, 2015) is of importance for many aspects of society, also concerning urban infrastructure, urban drainage and flood protection (e.g., Onof and Arnbjerg-Nielsen, 2009; Arnbjerg-Nielsen, 2012; Willems et al., 2012; Egger and Maurer, 2015). Because extreme rainfall over rather short periods (minutes-hours) is primarily responsible for flooding in urban systems, knowledge of changes in precipitation extremes at these high temporal resolutions and local (urban) scales is required. 
Hydrol. Earth Syst. Sci. Discuss., doi:10.5194/hess-2016-536, 2016

Manuscript under review for journal Hydrol. Earth Syst. Sci.

Published: 17 October 2016

(c) Author(s) 2016. CC-BY 3.0 License.

This presents a problem because (a) high-resolution gauges with 1-10 min sampling are not widespread globally, and even where they exist the records are usually not long enough to characterise uncertainty properly; and (b) predictions of precipitation change by climate models for the future are often only available at coarser daily resolutions averaged over large model grids and thus require downscaling. Only very recent climate modelling applications simulate precipitation changes at higher resolutions (hourly) and smaller spatial scales directly by resolving convection (e.g., Kendon et al., 2014; Ban et al., 2014, 2015).

Rising air temperature leads to a higher moisture holding capacity of the atmosphere and enhanced convective activity which is conducive to more intense precipitation (Trenberth et al., 2003). Data and modelling studies have shown that extreme intensities in particular increase with air temperature at rates of roughly $7-14 \%$ per ${ }^{\circ} \mathrm{C}$ (see review in Westra et al., 2014) and that this increase may in fact be attributed to anthropogenic warming (e.g., Fischer and Knutti, 2015). There is some indication from data that daily maximum precipitation has been increasing over time worldwide (e.g., Donat et al., 2013; Westra et al., 2013), but it is difficult to judge the uncertainty of this climate change signal and how it propagates to higher resolution timescales. In particular short duration rainfall extremes, which are by definition rare events, exhibit large variability. In the projection of changes in such events we need to confront predictions of climate models with internal climate variability (stochasticity) in rainfall itself, keeping in mind that multiple sources of uncertainty may affect the predictability of climate change impacts altogether (e.g., Kendon et al., 2008; Hawkins and Sutton, 2011; Fatichi et al., 2016).

One approach to detect climate change signals in rainfall extremes is to combine climate models with stochastic simulation techniques to generate precipitation time series at high temporal resolutions for present and future climates (see reviews, Fowler et al., 2007; Maraun et al., 2010). Global and Regional Climate Modelling (GCM-RCM) experiments in which many models and emission scenarios are combined, e.g. ENSEMBLES (van der Linden and Mitchell, 2009) and CMIP5 (Taylor et al., 2012), provide daily precipitation for present and future climates averaged over relatively coarse grid sizes $\sim 10-100 \mathrm{~km}$. These are used to compute statistics of precipitation change between future and current climate, which are then used to re-parametrise stochastic models for precipitation at the raingauge scale. In this stochastic downscaling process climate model information is transferred to the local scales and many possible realizations of climate are generated accounting for internal climate variability (e.g., Knutti, 2008; Koutsoyiannis et al., 2008; Onof and Arnbjerg-Nielsen, 2009; Burton et al., 2010; Fatichi et al., 2011, 2016). At local scales it can then be shown that uncertainty in climate change projections of precipitation extremes is mostly due to internal climate variability, and that the variability in current and future climates often overlap (Fatichi et al., 2016).

The stochastic downscaling approach we follow in this paper is that of a nested model consisting of a point process NeymannScott Rectangular Pulse Model (Cowpertwait, 1998) for daily rainfall and an embedded Multiplicative Random Cascade Model (Rupp et al., 2009) for 10-min rainfall presented by Paschalis et al. (2014). It falls into the category of stochastic rainfall weather generators (e.g., Kilsby et al., 2007; Fatichi et al., 2011). It has been shown that this combination of nested models provides the correct natural variability in different climates over a range of temporal scales and statistics important for urban hydrology (Paschalis et al., 2014).

In this work we build on the findings of Fatichi et al. (2016), which point to the importance of internal climate variability in climate change impact assessment, by extending the perspective to high-resolution 10-min timescales and long return period 
Hydrol. Earth Syst. Sci. Discuss., doi:10.5194/hess-2016-536, 2016

Manuscript under review for journal Hydrol. Earth Syst. Sci.

Published: 17 October 2016

(c) Author(s) 2016. CC-BY 3.0 License.

extremes which are important for urban drainage performance and design. The objectives in this work are (a) to present the stochastic simulator and apply it to a selection of 22 raingauges in Switzerland; and (b) to quantify the impact of climate change as simulated by the ENSEMBLES Project on high-resolution precipitation extremes at these stations. The main underlying question we address is: Are impacts of climate change on rainfall extremes at resolutions from 10-min to 1-day beyond the range of internal climate variability in rainfall, and what could be the implications for urban hydrology?

\section{Data}

The raingauge data used in this analysis come from a selection of 22 meteorological stations of the SwissMetNet network (Meteoswiss) for the observation period 1981-2010. The stations were chosen to be approximatelly uniformly distributed across Switzerland north and south of the main Alpine divide (Fig 1). The stations are more representative of Alpine forelands, valleys and urban areas, being mostly at elevations around $500 \mathrm{~m}$, thereby undersampling the high elevations. The raingauges are heated tipping-bucket instruments with 10-min sampling and accuracy $0.1 \mathrm{~mm}$ (tip volume). Standard data quality control is performed by MeteoSwiss to eliminate errors and spurious measurements. These data have been used for investigations of multiscaling properties (Molnar and Burlando, 2008), analysis of storm convectivness (Gaal et al., 2014), and precipitation intensity-air temperature relations (Molnar et al., 2015). In terms of precipitation change in Switzerland there is some evidence of increases in daily maxima (Frei and Schaer, 2001), but hourly precipitation changes show a more complex and inconclusive pattern, with the exception of increases in late afternoon rainfall in summer (Fatichi et al., 2015).

The GCM-RCM model simulations are from the ENSEMBLES Project (van der Linden and Mitchell, 2009) and are described in detail in Egger and Maurer (2015). We use ten different models under the A1B greenhouse gas emission scenario. The control run for the current climate coincides with observations (1981-2010), while for the future runs we use a near future (2035-2064) and a far future (2070-2099) scenario. Climate model runs for the near future were extracted for grids which contained the 22 meteorological stations. For the far future we constrain the analysis to 4 selected stations in distinct regions in Switzerland (Lugano, Waedenswil, Basel, Geneva). The daily precipitation data from GCM-RCM runs were used to estimate first and higher order statistics as well as autocorrelation and intermittency for each month (see Section 3). Every climate model was analyzed and treated independently and realizations were not averaged or combined as done by some other studies (e.g., Tebaldi et al., 2005; Fatichi et al., 2013). Throughout this article we use Lugano as an example station, results for the remaining 3 selected stations in the main geoclimatic regions in Switzerland are available in Supplementary materials.

\section{Methods}

The methodology to quantify the strength of the climate change signal on precipitation follows Fatichi et al. (2011) and is based on a Factor of Change approach. First, the natural variability in precipitation extremes under the current climate is quantified by estimating the stochastic simulator model parameters from raingauge observations and simulating precipitation with these parameters. Second, precipitation under future climate scenarios is generated with the parameters corresponding to future 
Hydrol. Earth Syst. Sci. Discuss., doi:10.5194/hess-2016-536, 2016

Manuscript under review for journal Hydrol. Earth Syst. Sci.

Published: 17 October 2016

(c) Author(s) 2016. CC-BY 3.0 License.

climate given by Factors of Change derived by 10 climate models and applied to precipitation statistics. In each case $n=100$ realisations each 30-yrs long are simulated. A comparison of the variability in precipitation extremes between projected future climate and current climate is finally made. The stochastic simulator of precipitation (Paschalis et al., 2014) allows us to easily deal with internal stochastic variability which is expected to be the dominant source of uncertainty in precipitation extremes (Fatichi et al., 2016). The method is schematically shown in Fig 2 and the key steps are explained in more detail here.

\subsection{Stochastic Simulator}

The stochastic simulator is a composite model which generates daily precipitation with prescribed statistical properties with a point process model and then disaggregates it to high temporal resolutions with a multiplicative random cascade approach. Paschalis et al. (2014) showed that this combination and nesting of models leads to better overall performance across a wider range of temporal scales than using single models alone. In this work we chose the Neyman-Scott Rectangular Pulse model (NSRP) as the external model for daily precipitation and as the internal model we tested two versions of the Multiplicative Random Cascade (MRC) for disaggregation to 10-min resolutions (Fig 2). A similar combination of models was also used by Onof and Arnbjerg-Nielsen (2009).

The external NSRP model belongs to point-process models of the Poisson cluster type with many successful applications in rainfall simulation (e.g., Rodriguez-Iturbe et al., 1988; Onof et al., 2000; Burton et al., 2010). The model conceptualizes rainfall as consisting of a random sequence of storms, each consisting of one or more overlapping or spaced raincells with a given intensity and duration. The required storm properties are: (a) storm origin (Poisson) arrival rate; (b) number of raincells in a storm; (c) the starting time of a raincell from storm origin; (d) raincell duration; and (e) raincell intensity. Probability distributions are assumed for all of the above variables and their parameters are estimated by numerical optimization comparing sample and theoretical statistics of precipitation at different scales (see Cowpertwait, 1998, 2004; Cowpertwait et al., 2007). Statistics used in the optimization are mean, coefficient of variation, lag-1 autocorrelation, probability of zero precipitation and skewness, all estimated at temporal scales 1, 6, 12, 24, 48 and $72 \mathrm{hrs}$. Although the NSRP model is used to simulate daily precipitation, we also use sub-daily data in the calibration as some rainfall properties have to be estimated at higher resolution to be accurate, e.g. storm duration.

The internal MRC model uses the concept of scaling to disaggregate rainfall across temporal scales by so called cascade generator weights $W$ which multiply rainfall depth at an ordinate scale to get the rainfall depth at the embedded subordinate scale. In this subdivision, rainfall may be preserved exactly (micro-canonically) or statistically (macro-canonically), which determines the nature and form of the cascade generator weights. The parameters of the model are statistics describing the probability distributions of the generator weights $f(W)$ and their scale dependence. The MRC model is popular mainly because of its intuitive nature in generating fluctuations in intensities at high resolutions, which determines its success for extremes and makes it useful for many practical applications (e.g., Olsson, 1998; Molnar and Burlando, 2005; Rupp et al., 2009; Onof and Arnbjerg-Nielsen, 2009; Paschalis et al., 2012). In this work we use the discrete micro-canonical version of the MRC model in order to preserve the disaggregated daily rainfall simulated by the external NSRP model. We allow for the generation of 
Hydrol. Earth Syst. Sci. Discuss., doi:10.5194/hess-2016-536, 2016

Manuscript under review for journal Hydrol. Earth Syst. Sci.

Published: 17 October 2016

(c) Author(s) 2016. CC-BY 3.0 License.

intermittency, i.e. zero rainfall, when the cascade generator $W=0$, and we assign a probability to this case which is resolution dependent.

Originally the MRC model was built on the assumption of independent and identically distributed (iid) weights $W$ over the entire range of disaggregation scales. Data-based investigations have shown that the weights are in fact scale and intensity dependent (e.g., Carsteanu and Foufoula-Georgiou, 1996; Menabde and Sivapalan, 2000; Rupp et al., 2009; Serinaldi, 2010; Paschalis et al., 2012). In the stochastic simulator we therefore use two versions of scale-dependent generators formalised by Rupp et al. (2009): MRCA (Model A) where $f(W)$ depends on the temporal scale of aggregation from 1-day to 10-mins and $\operatorname{Pr}(W=0)$ depends both on temporal scale and intensity of rain; and MRCB (Model B) where also the distribution $f(W)$ is dependent on both temporal scale and intensity of rain. The parameters of both models are estimated by coarse-graining the raingauge 10-min data in doubling scales to approximately 1-day and estimating the distributions $f(W)$ as a function of temporal scale and rain intensity. Further details about the MRC models and their parametrisation can be found in Rupp et al. (2009) and Paschalis et al. (2014).

\subsection{Future Climate Factors of Change}

Climate model simulations of precipitation are used to derive Factors of Change (FoC) which are then applied to chosen key statistics of precipitation. The external NSRP model is re-parametrised with the new statistics and used to simulate precipitation for the future climate. The FoC are computed as ratios of the statistics of precipitation for the future (FUT) scenarios simulated by the 10 chosen climate models for two future horizons: near future (2035-2064) and far future (2070-2099), and the control period (CTS) for the current climate. It should be mentioned that this use of FoC assumes that statistics of areally-averaged rainfall simulated by climate models reflect changes at the point raingauge scale (e.g., Kilsby et al., 2007; Onof and Arnbjerg-

20 Nielsen, 2009). This is an acceptable assumption considering that spatial variability of FoC in a single climate model is expected to be much smaller than FoC variability between models (e.g., Fatichi et al., 2011).

We use the 10 GCM-RCM model chains individually to derive 10 FoC groups for every statistic (Egger and Maurer, 2015). The FoC are developed for all statistics required to re-parametrise the NSRP model, i.e. mean, coefficient of variance, lag- 1 auto correlation and probability of zero precipitation and skewness at six different time scales 1, 6, 12, 24, 48 and $72 \mathrm{hrs}$. As GCM-RCMs outputs are available only at daily temporal scales, the FoC for sub-daily resolutions have to be extrapolated to these resolutions by methods suitable for that purpose. While this is trivial for first order statistics, for higher order statistics such as variance we use the scaling method of Marani and Zanetti (2007), the probability of zero rainfall (intermittency) we fit with a power function at coarse resolutions (Molnar and Burlando, 2005), the lag-1 autocorrelation at sub-daily scales was not used in the calibration, and skewness was assumed to be independent of the temporal resolution.

The choice of the daily timescale for the nesting of the MRC model into the NSRP model has to do with (a) the demonstrated skill of the NSRP model at daily scales (e.g., Onof and Arnbjerg-Nielsen, 2009; Paschalis et al., 2014); and (b) the fact that climate change simulations are usually provided at daily resolution, so FoC are appropriately applied to the NSRP model only. FoC are not applied to the internal MRC models because we assume here that the sub-daily processes of rainfall formation are independent of climate change and are only indirectly affected through the external process. In fact, a climate change signal 
Hydrol. Earth Syst. Sci. Discuss., doi:10.5194/hess-2016-536, 2016

Manuscript under review for journal Hydrol. Earth Syst. Sci.

Published: 17 October 2016

propagates from daily to 10-min scales only through changes in rain intensity to which the MRC parameters are related. This is a limitation of the model which has important implications and some possible solutions which will be outlined later.

\section{Results and Discussion}

\subsection{Validation of the Stochastic Simulator}

5 The stochastic simulator was calibrated with 10-min data from the 22 meteorological stations for the control climate period 1981-2010. The model was validated based on a comparison of key observed and simulated statistics from $n=100$ realizations. We show results of this comparison for the NSRP-MRCA (Fig 3) and NSRP-MRCB (Fig 4) model combinations for the Lugano station. Model performance is very similar between the 22 stations (other 3 main station result sheets can be found in Supplementary materials).

10 Model performance is tested at three time resolutions: 10-min, 1-hr and 24-hr. The coarsest 24-hr resolution reflects the performance of the external NSRP model, while the 1-hr and 10-min resolutions capture the differences between the internal MRCA and MRCB disaggregation models. The 10-min resolution is critical for capturing short pulses of high intensity rainfall and is important for urban drainage system analysis which motivates this research. The 1-hr resolution is important for the flood response of most medium-sized catchments which have response times on the order of several hours, and for natural hazards connected to soil saturation (landslides, debris flows, etc.). The daily resolution is important for large catchments and long-lasting storms which usually generate combined hazards, especially in Alpine areas.

The five main statistics of precipitation (mean, standard deviation, skewness, lag-1 correlation, and intermittency) are generally very well reproduced by the stochastic simulator at all resolutions (Figs 3 and 4 for Lugano). Because the external NSRP model is parameterized for every month, seasonal properties of precipitation are shown. First-order moments are perfectly reproduced by all models by construction. For the other statistics the performance is overall best for the daily resolution where only the NSRP model matters. At the 10-min resolution the results are also good, with small departures in the summer season serial correlation and skewness. The MRCB model is slightly better than the MRCA model in reproducing the correlation structure, due to the added parametrisation of cascade weights $W$ on rain intensity (Paschalis et al., 2014), and we use it for the remainder of the analysis. This result was true for most of the studied stations. The problem of the underestimation of serial correlation in MRC models is known and has been ascribed to the temporal independence in cascade weights assumed in such models (Paschalis et al., 2012) and to the discrete nature of the cascade (Lombardo et al., 2012).

The good performance of the stochastic simulator (including correlation and intermittency) at all temporal scales reflects in a good performance for extremes as well. In most cases the 10-90\% confidence bounds on the distributions of simulated annual maxima for all analysed durations contain the observations, such as in the Lugano example (Figs $3 \mathrm{f}$ and $4 \mathrm{f}$ ). This result was reproduced at the other stations as well. This is not a trivial outcome since the stochastic simulator is not explicitly calibrated to reproduce annual maxima. 
Hydrol. Earth Syst. Sci. Discuss., doi:10.5194/hess-2016-536, 2016

\subsection{Extremes and Climate Change}

Simulated mean extremes fit observations very well at all stations, for all three studied time resolutions and return periods: 5, 10, and 30 years (Fig 5). There is a remarkable consistency in performance for this range of return periods important for urban hydrologic design, despite the large variability in climatology at the individual stations. The bias averaged across all stations ranged between $-9-4 \%$ for $10-$ min extremes, $0-5 \%$ for $1-\mathrm{hr}$ extremes and $2-4 \%$ for $24-\mathrm{hr}$ extremes across the studied return periods. It should be noted that the annual extremes are usually summer convective events, which is the season where model performance with regard to serial correlation and skewness was the poorest.

To make statistically sound statements about the climate change signal in rainfall extremes it is necessary to compare the extreme value statistics projected for the future climate with those for the current climate considering internal climate variability (stochastic uncertainty). In Fig 6 this is done for all 10 model runs for the three return periods, temporal resolutions, and both future time periods for the Lugano station. Statistics for the current climate annual maxima are shown with mean (horizontal solid line) and 10-90\% uncertainty bounds on the mean from $n=100$ realizations (horizontal dashed lines). We assume that if climate projections lie outside this range, a practically meaningful signal of changes in extremes which goes beyond historical expectation is present. The results for all models are presented individually so that stochastic downscaling for different models can be compared.

The results show that the distributions of extremes for the future and current climate largely overlap. The mean annual extremes for a given return period lie outside of the 10-90\% uncertainty bound of the current climate in relatively few cases. For example, for the near future (2035-2064) it is between 4-15\% of the analyzed cases for the 10-min extremes, 6-15\% for the 1-hr extremes and 14-22\% for the 24-hr extremes depending on return period (Fig 7). It is notable that both increases and decreases in future climate extremes are generated by different models, and that individual models are consistent across temporal scales and return periods. The predicted changes in the mean outside of current climate variability at the 24-hr resolution were all positive, while for the 10-min scale there were several negative changes as well. As expected, for longer return periods the uncertainty increases and changes are less than 5\% for the 10-min extremes. The strongest signal containing almost only increases in rainfall was naturally in the daily extremes where FoC were applied to the NSRP Model (Fig 7). The results for the remaining three stations where far future climate was examined were similar. Overall this result points to the fact that internal climate variability expressed as stochastic uncertainty in rainfall extremes is extremely large in the current climate especially for short duration extremes, and that mean predictions for the future are likely to lie within this variability. This makes statements about future climate change impacts on rainfall extremes very uncertain. In fact in the absence of considerable departures, it may be concluded that the climate change impact on high-resolution rainfall extremes may be difficult or impossible to characterise.

We highlight two main limitations which can be removed in future work. First, emission scenario uncertainty is not considered, as only one emission scenario (A1B) is considered. If it is desirable to analyse more emission scenarios, emission uncertainty bounds can be built on top of the climate model uncertainty as was done by Fatichi et al. (2016). Note however that for precipitation extremes emission scenarios contribute very little to the overall uncertainty. Second, the parameters of 
Hydrol. Earth Syst. Sci. Discuss., doi:10.5194/hess-2016-536, 2016

the internal MRC disaggregation model remain unchanged in a future climate. This does not mean that the MRC model is totally insensitive to a climate change because the cascade weight distributions $f(W)$ and intermittency are intensity-dependent. Therefore, insofar as the external NSRP model simulates an increase in rainfall intensity through FoCs, this will propagate into the disaggregation model. However, it is possible to make the parameters of the cascade weight distributions explicitly dependent on some climate sensitive variable such as air temperature. In this way consistent relationships between rain intensity at sub-daily timescales and daily air temperature which have been observed in precipitation data may be recovered in simulation. This is an important deterministic signal related to the increase in the moisture-holding capacity of air with temperature (Clausius-Clapeyron law) that cannot be reproduced by our stochastic simulator, but it will very likely affect climate change precipitation extremes at high temporal resolutions. There is theoretical, modelling and observational evidence which supports this increase of rainfall intensity with air temperature (e.g., Loriaux et al., 2013; Berg et al., 2013; Westra et al., 2014; Molnar et al., 2015; O'Gorman, 2015; Ban et al., 2015; Moseley et al., 2016). In fact, first attempts have been made to show that MRC models can be parametrised with temperature to recover the Clausius-Clapeyron relation (Bürger et al., 2014) and future research should be directed to this task.

\section{Conclusions}

A stochastic rainfall simulation application through which coarse grid-based climate model predictions of precipitation change may be stochastically downscaled into station-level time series of rainfall down to 10-min temporal resolution is presented. In this framework, annual extremes with different exceedance probabilities are analysed for the current and future climates, and changes can be confronted with internal climate variability (stochasticity) in extremes. The inclusion of internal climate variability is key, because we confirm that for precipitation it is a dominant type of uncertainty, fundamentally masking predictability of vital details of climate change (Fatichi et al., 2016).

The first result of the work is the demonstration of the successful performance of the stochastic simulator which nests two different stochastic rainfall models across scales (Paschalis et al., 2014) for the current climate across 22 meteorological stations in Switzerland. We have shown that not only basic statistics for temporal scales from 10-min to 24-hr are well reproduced by the model, but also correlation structure, intermittency and skewness. Some small departures are present in summer seasons for higher order statistics, probably due to the fluctuations in summer convective storms which are difficult to capture with the disaggregation model. Most notably, the performance of the stochastic simulator for mean annual maxima for a range of return periods relevant for urban hydrology (5-30 years) and all temporal resolutions studied (10-min, 1-hr, 24-hr) was remarkable, with mean bias in the range $-9-4 \%$ (Fig 5), especially considering that statistics of extremes are not used in the calibration procedure.

30 The second result concerns the climate change signal in rainfall extremes. We have shown that the distributions of annual maxima for the current and future climates for multiple stations and durations largely overlap. The mean annual extremes for a given return period lie outside of the 10-90\% uncertainty bound of the current climate in relatively few cases (Fig 6). Most notably, both increases and decreases in future climate extremes are generated by the different GCM-RCM model chains, 
Hydrol. Earth Syst. Sci. Discuss., doi:10.5194/hess-2016-536, 2016

Manuscript under review for journal Hydrol. Earth Syst. Sci.

Published: 17 October 2016

(c) Author(s) 2016. CC-BY 3.0 License.

(c) (i)
Hydrology and

Earth System

Sciences

Discussions

and this depends on timescale and return period (Fig 7). Our results provide confirmation that natural climate variability in rainfall extremes is very large in the current climate, and because predictions for the future are often contained within this variability, caution is required when making statements about future climate change impacts on rainfall extremes at a high temporal resolution (e.g. 10-min).

5 We conclude that the climate change signal in rainfall extremes generated by climate models may have little practical value if the large irreducible stochasticity present in this variable is not considered. At the same time, we underline that including current climate variability in rainfall extremes for urban hydrological applications is vital, and we propose it may in fact already cover a large part of the uncertainty connected with climate change in the future (e.g., Fatichi et al., 2016). A potentially important exception relates to a deterministic signal imposed by the Clausius-Clapeyron law on high temporal resolution rainfall extremes, which is currently not reproduced by stochastic disaggregation models. Its inclusion is possible and should be the subject of future research.

\section{Code availability}

The Matlab code for the numerical analysis may be requested from the authors.

\section{Data availability}

15 SwissMetNet rainfall data may be requested directly from Meteoswiss. The climate model simulations were donwloaded from the ENSEMBLES project.

Author contributions. BK performed the analysis. PM wrote the main part of the article. AP is author of the stochastic simulator and coded the application for this paper. SF, MM and PM conceived the research and contributed to the manuscript.

Competing interests. There are no competing interests.

Acknowledgements. Meteoswiss is acknowledged for providing the 10-min rainfall data for this research. The ENSEMBLES project provided the climate model data. The development of the stochastic simulator was funded by the SNF 20021-120310 grant awarded to PM. Frank Blumensaat and Christoph Egger are acknowledged for providing assistance to $\mathrm{BH}$. 
Hydrol. Earth Syst. Sci. Discuss., doi:10.5194/hess-2016-536, 2016

Manuscript under review for journal Hydrol. Earth Syst. Sci.

Published: 17 October 2016

(c) Author(s) 2016. CC-BY 3.0 License.

\section{References}

Arnbjerg-Nielsen, K. (2012), Quantification of climate change effects on extreme precipitation used for high resolution hydrologic design. Urban Water Journal, 9, 2, 57-65, doi:10.1080/1573062X.2011.630091.

Ban, N., J. Schmidli, and C. Schär (2014), Evaluation of the convection-resolving regional climate modeling approach in decade-long simulations. J. Geophys. Res. Atmos., 119, 7889-7907, doi:10.1002/2014JD021478.

Ban, N., J. Schmidli, and C. Schär (2015), Heavy precipitation in a changing climate: Does short-term summer precipitation increase faster? Geophys. Res. Lett., 42, 1165-1172, doi:10.1002/2014GL062588.

Berg, P., Moseley, C., and Haerter, J. O. (2013). Strong increase in convective precipitation in response to higher temperatures, Nat. Geosci., 6, 181-185, doi:10.1038/NGEO1731.

Burton, A., Fowler, H. J., Blenkinsop, S. and Kilsby, C. G. (2010), Downscaling transient climate change using a Neyman-Scott Rectangular Pulses stochastic rainfall model. Journal of Hydrology, 381, 18-32, doi:10.1016/j.jhydrol.2009.10.031.

Bürger, G., Heistermann, M., and A. Bronstert (2014), Towards subdaily rainfall disaggregation via Clausius-Clapeyron, J. Hydrometeorology, 1303-1311, doi:10.1175/JHM-D-13-0161.1.

Carsteanu A., and Foufoula-Georgiou E. (1996), Assessing dependence among weights in a multiplicative cascade model of temporal rainfall.

J Geophys Res D Atmos, 101, 26,363-26,370,doi:10.1029/96JD01657.

Cowpertwait, P. S. P. (1998), A Poisson-cluster model of rainfall: some high-order moments and extreme values. Proceedings of the Royal Society A: Mathematical, Physical and Engineering Sciences, 454, 885-898, doi:10.1098/rspa.1998.0191.

Cowpertwait, P. S. P. (2004), Mixed rectangular pulses models of rainfall. Hydrol. Earth Syst. Sci., 8, 993-1000.

Cowpertwait, P. S. P., V. Isham, and C. Onof (2007), Point process models of rainfall: developments for fine-scale structure, Proc. R. Soc. Lond. A, 463(2086), 2569-2587, doi:10.1098/rspa.2007.1889.

Donat, M. G., et al. (2013), Updated analyses of temperature and precipitation extreme indices since the beginning of the twentieth century: The HadEX2 dataset. J. Geophys. Res. Atmos., 118, 2098-2118, doi:10.1002/ jgrd.50150.

Egger, C. and Maurer, M. (2015), Importance of anthropogenic climate impact, sampling error and urban development in sewer system design. Water Research,73, 78-97.

Fatichi, S., Ivanov, V. Y. and Caporali, E. (2011), Simulation of future climate scenarios with a weather generator. Advances in Water Resources 34, 448-467, doi:10.1016/j.advwatres.2010.12.013.

Fatichi, S., V. Y. Ivanov, and E. Caporali (2013), Assessment of a stochastic downscaling methodology in generating an ensemble of hourly future climate time series, Clim. Dyn., 40, 1841-1861, doi:10.1007/s00382-012-1627-2.

Fatichi, S., Molnar, P., Mastrotheodoros, T., and P.Burlando (2015), Diurnal and seasonal changes in near surface humidity in a complex orography. J. Geophys. Res.-Atmos., 120, doi:10.1002/2014JD022537.

Fatichi, S., Ivanov, V. Y., Pascalis, A., Peleg, N., Molnar, P., Rimkus, S., Kim, J., Burlando, P. and Caporali, E. (2016), Uncertainty partition challenges the predictability of vital details of climate change. Earth's Future, 4, 240-251, doi:10.1002/2015EF000336.

Fischer E. M., and R. Knutti (2015), Anthropogenic contribution to global occurrence of heavy-precipitation and high-temperature extremes. Nature Climate Change, 5, 560-564, doi:10.1038/nclimate2617.

Fowler, H. J., S. Blenkinsop, and C. Tebald (2007),Linking climate change modelling to impacts studies: recent advances in downscaling techniques for hydrological modelling. Int. J. Climatol., 27, 1547-1578, doi:10.1002/joc.1556. 
Hydrol. Earth Syst. Sci. Discuss., doi:10.5194/hess-2016-536, 2016

Manuscript under review for journal Hydrol. Earth Syst. Sci.

Published: 17 October 2016

(c) Author(s) 2016. CC-BY 3.0 License.
Hydrology and

Earth System

Sciences

Discussions

(c) (i)

Frei, C. and Schaer, C. (2001), Detection probability of trends in rare events: Theory and application to heavy precipitation in the Alpine region, J. Climate, 14, 1568-1584, doi:10.1175/1520-0442.

Gaal, L., Molnar, P., and Szolgay, J. (2014), Selection of intense rainfall events based on intensity thresholds and lightning data in Switzerland. Hydrol. Earth Syst. Sci, 18, 1561-1573, doi:10.5194/hess-18-1561-2014.

5 Hawkins, E., and R. Sutton (2011), The potential to narrow uncertainty in projections of regional precipitation change, Clim. Dyn., 37, 407-418, doi:10.1007/s00382-010-0810-6.

Kendon, E. J., Rowell, D. P., Jones, R. G. and Buonomo E. (2008), Robustness of Future Changes in Local Precipitation Extremes. J. Clim. 21, 4280-4297.

Kendon, E. J., Roberts, N. M., Fowler, H. J., Roberts, M. J., Chan, S. C., and C. A. Senior (2014), Heavier summer downpours with climate change revealed by weather forecast resolution model. Nature Climate Change, 4, 570-576, doi:10.1038/NCLIMATE2258.

Kilsby, C.G., Jones, P.D., Burton, A., Ford, A.C., Fowler, H.J., Harpham, C., Jamesa, Smith, P.A., Wilby, R.L., (2007), A daily weather generator for use in climate change studies. Environmental Modelling and Software, 22, 12, 1705-1719.

Koutsoyiannis, D., Efstratiadis, A., Mamassis, N. and Christofides, A. (2009), On the credibility of climate predictions. Hydrological Sciences Journal 53, 671-684.

15 Knutti, R. (2008), Should we believe model predictions of future climate change? Philosophical transactions. Series A, Mathematical, physical, and engineering sciences, 366, 4647-4664, doi:10.1098/rsta.2008.0169.

Loriaux, J. M., Lenderink, G., De Roode, S. R., and Pier Siebsma, A. (2013), Understanding convective extreme precipitation scaling using observations and an entraining plume model, J. Atmos. Sci., 70, 3641-3655, doi:10.1175/JAS-D-12-0317.1.

Marani, M, and S. Zanetti (2007), Downscaling rainfall temporal variability. Water Resour. Res., 43, W09415, doi:10.1029/2006WR005505.

Maraun, D., et al. (2010), Precipitation downscaling under climate change: recent developments to bridge the gap between dynamical models and the end user, Rev. Geophys., 48, RG3003, doi:10.1029/2009RG000314.

Moseley, C., Hohenegger, C., Berg, P., and J. O. Haerter (2016), Intensification of convective extrmes driven by cloud-cloud interaction, Nature Geosci., 9, 748-752.

Menabde M., and Sivapalan M. (2000), Modeling of rainfall time series and extremes using bounded random cascades and Levy-stable distributions. Water Resour Res, 36, 3293-300, doi:10.1029/2000WR900197.

Molnar P. and Burlando P. (2005), Preservation of rainfall properties in stochastic disaggregation by a simple random cascade model. Atmos Res., 77, 137-51, doi:10.1016/j.atmosres.2004.10.024.

Molnar, P. and Burlando, P. (2008), Variability in the scale properties of high-resolution precipitation data in the Alpine climate of Switzerland. Water Resour. Res., 44, W10404, doi:10.1029/2007WR006142.

Molnar, P., Fatichi, S., Gaal, L., Szolgay, J., and P. Burlando (2015), Storm type effects on super Clausius-Clapeyron scaling of intense rainstorm properties with air temperature. Hydrol. Earth Syst. Sci., 19, 1753-1766, doi:10.5194/hess-19-1753-2015.

O’Gorman, P. A. (2015), Precipitation extremes under climate change, Curr. Clim. Change Rep., 1, 49-59. doi:10.1007/s40641-015-0009-3.

Olsson, J. (1998), Evaluation of a scaling cascade model for temporal rainfall disaggregation. Hydrol Earth Syst Sci 1998, 2, 19-30, doi:10.5194/hess-2-19-1998.

35 Onof, C., Chandler, R. E., Kakou, A., Northrop, P., Wheater, H. and Isham, V. (2000), Rainfall modelling using Poisson-cluster processes: a review of developments. Stochastic Environmental Research and Risk Assessment, 14, 384-411.

Onof, C., and Arnbjerg-Nielse, K. (2009), Quantification of anticipated future changes in high resolution design rainfall for urban areas. Atmosph. Res., 92, 3, 350-363, doi:10.1016/j.atmosres.2009.01.014. 
Hydrol. Earth Syst. Sci. Discuss., doi:10.5194/hess-2016-536, 2016

Manuscript under review for journal Hydrol. Earth Syst. Sci.

Published: 17 October 2016

(c) Author(s) 2016. CC-BY 3.0 License.
Hydrology and

Earth System

Sciences

Discussions

(c) (i)

Paschalis, A., Molnar, P., and Burlando, P. (2012), Temporal dependence structure in weights in a multiplicative cascade model for precipitation. Water Resour. Res., 48, W01501, doi:10.1029/2011WR010679.

Paschalis, A., Molnar, P., Fatichi, S. and Burlando, P. (2013), On temporal stochastic modeling of precipitation: nesting models across scales. Advances in Water Resources, 63, 152-166,

5 Rodriguez-Iturbe, I., Cox, D. R. and Isham, V. (1988), A Point Process Model for Rainfall: Further Developments. Proceedings of the Royal Society A: Mathematical, Physical and Engineering Sciences 417, 283-298, doi:10.1098/rspa.1988.0061.

Rupp, D., Keim, R., Ossiander, M., Brugnach, M. and Selker, J. (2009), Time scale and intensity dependency in multiplicative cascades for temporal rainfall disaggregation. Water Resources Research 45, doi:10.1029/2008WR007321.

Serinaldi, F. (2010), Multifractality, imperfect scaling and hydrological properties of rainfall time series simulated by continuous universal multifractal and discrete random cascade models. Nonlinear Process Geophys, 17, 697-714, doi:10.5194/npg-17-697-2010.

Taylor,K. E.,R. J. Stouffer, andG.A. Meehl (2012), An overview of the CMOP5 and the experimental design,. Bull. Amer. Meteorol. Soc.,93, 4, 485-498, doi:10.1175/bams-d-11-00094.1.

Tebaldi, C., R. L. Smith, D. Nychka, and L. O. Mearns (2005), Quantifying uncertainty in projections of regional climate change: a Bayesian approach to the analysis of multi-model ensembles, J. Clim., 18, 1524-1540, doi:10.1175/jcli3363.1.

Trenberth, K. E., Dai, A., Rasmussen, R. M., and Parsons, D. B. (2003), The changing character of precipitation. B. Am. Meteorol. Soc., 84, 1205-1217, doi:10.1175/BAMS-84-9-120.

Veneziano, D. and Langousis, A. (2010), Scaling and fractals in hydrology. In Advances in Data-based Approaches for Hydrologic Modeling and Forecasting.

van der Linden, P., Mitchell, J.F.B., (2009), ENSEMBLES: Climate Changes and its Impacts: Summary of Research and Results from the ENSEMBLES Project. Met Office Hadley Centre, FitzRoy Road, Exeter EX1 3PB, UK, p. 160.

Lombardo, F., Volpi, E., and D. Koutsoyiannis (2012), Rainfall downscaling in time: Theoretical and empirical comparison between multifractal and Hurst-Kolmogorov discrete random cascades. Hydrological Sciences Journal, 57, 6, 1052-1066.

Westra, S., Alexander, L. V., andF. W. Zwiers (2013), Global increasing trends in annual maximum daily precipitation. J. Climate, 26, 3904-3918, doi:10.1175/JCLI-D-12-00502.1.

25 Westra, S., Fowler, H. J., Evans, J. P., Alexander, L. V., Berg, P., Johnson, F., Kendon, E. J., Lenderink, G., and Roberts, N. M. (2014), Future changes to the intensity and frequency ofshort-duration extreme rainfall. Rev. Geophys., 52, 522-555, doi:10.1002/2014RG000464.

Willems, P., Arnbjerg-Nielsen,K., Olsson, J., and V.T.V. Nguyen (2012), Climate change impact assessment on urban rainfall extremes and urban drainage: Methods and shortcomings. Atmos. Res., 103, 106-118, doi:10.1016/j.atmosres.2011.04.003. 
Hydrol. Earth Syst. Sci. Discuss., doi:10.5194/hess-2016-536, 2016

Manuscript under review for journal Hydrol. Earth Syst. Sci.

Published: 17 October 2016

(c) Author(s) 2016. CC-BY 3.0 License.
Hydrology and

Earth System

Sciences

Discussions

(c) $($ i)

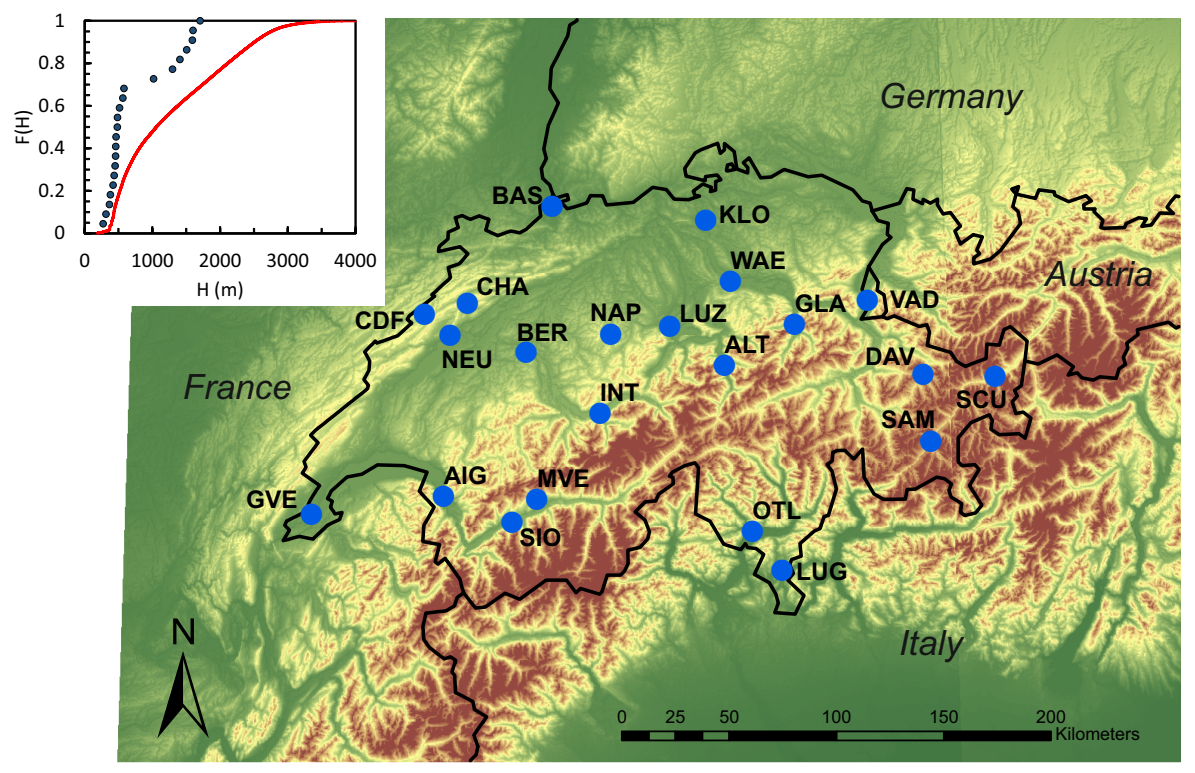

Figure 1. Locations of the 22 studied MeteoSwiss stations in Switzerland. Inset gives the elevation distribution in the country (red) from the 100-m SRTM-DEM, together with the elevation distribution of the stations (blue markers).

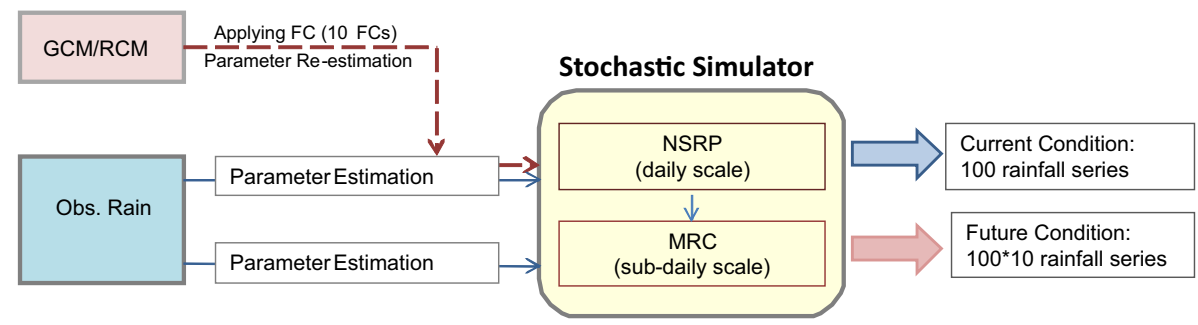

Figure 2. Schematic representation of the stochastic modelling approach. 
Hydrol. Earth Syst. Sci. Discuss., doi:10.5194/hess-2016-536, 2016

Manuscript under review for journal Hydrol. Earth Syst. Sci.

Published: 17 October 2016

(c) Author(s) 2016. CC-BY 3.0 License.

(c) (i)
Hydrology and
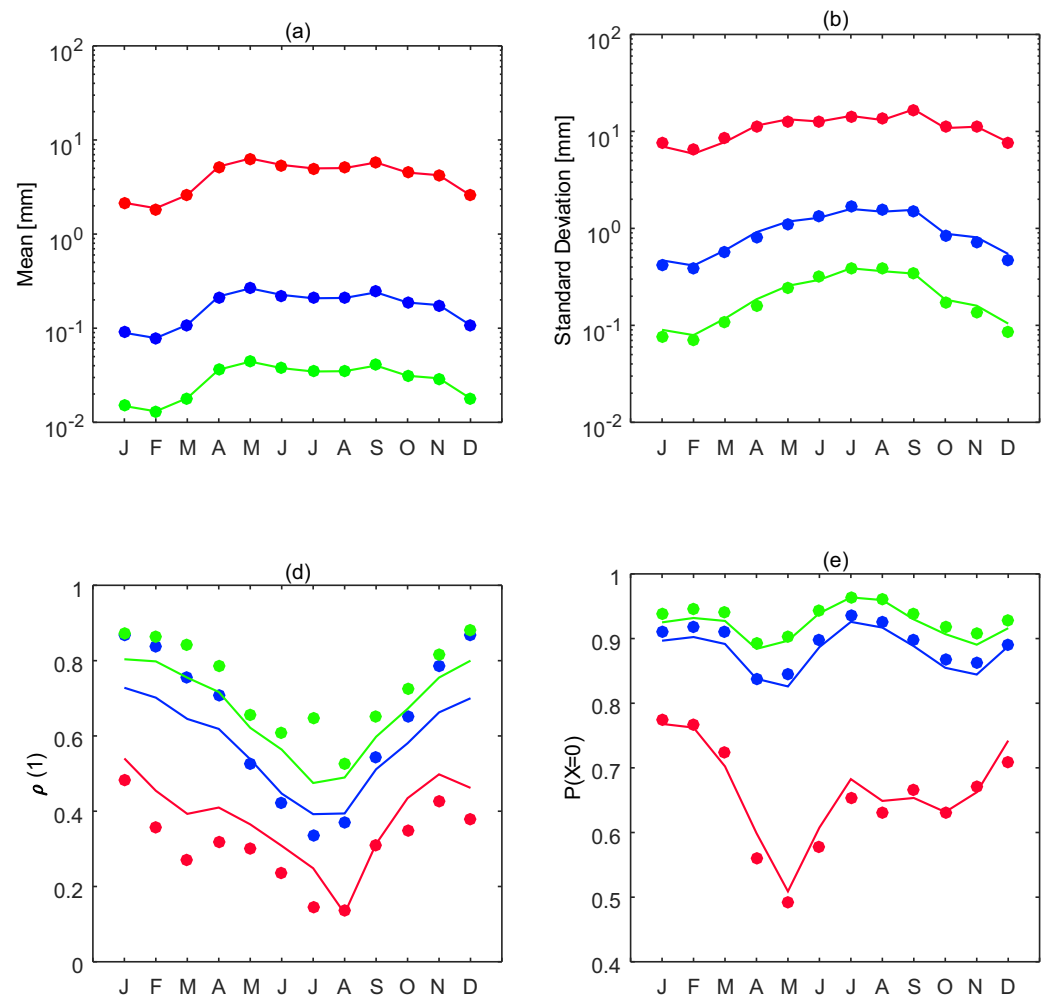
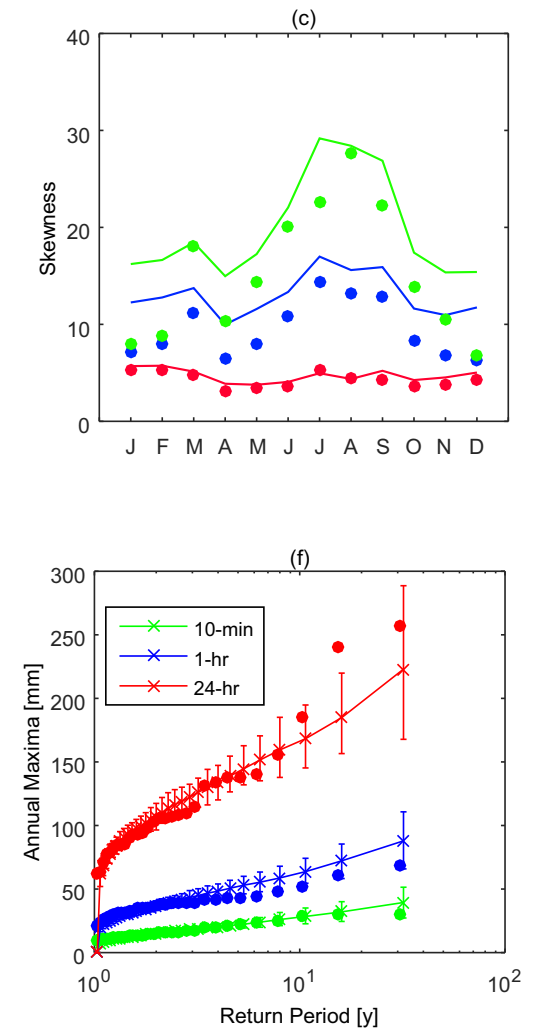

Figure 3. Simulated vs. observed monthly (a) mean precipitation, (b) standard deviation, (c) skewness, (d) lag-1 auto correlation, (e) probability of no rain, and (f) distribution of annual precipitation maxima for station Lugano at three temporal scales, with NSRP+MRCA. Markers represent observations and lines simulated values. In the simulated annual maxima distrubutions the mean and 10-90\% uncertainty bounds from $n=100$ simulations are shown. 
Hydrol. Earth Syst. Sci. Discuss., doi:10.5194/hess-2016-536, 2016

Manuscript under review for journal Hydrol. Earth Syst. Sci.

Published: 17 October 2016

(c) Author(s) 2016. CC-BY 3.0 License.

\section{(c) (1)}

Hydrology and

Earth System

Sciences

Discussions
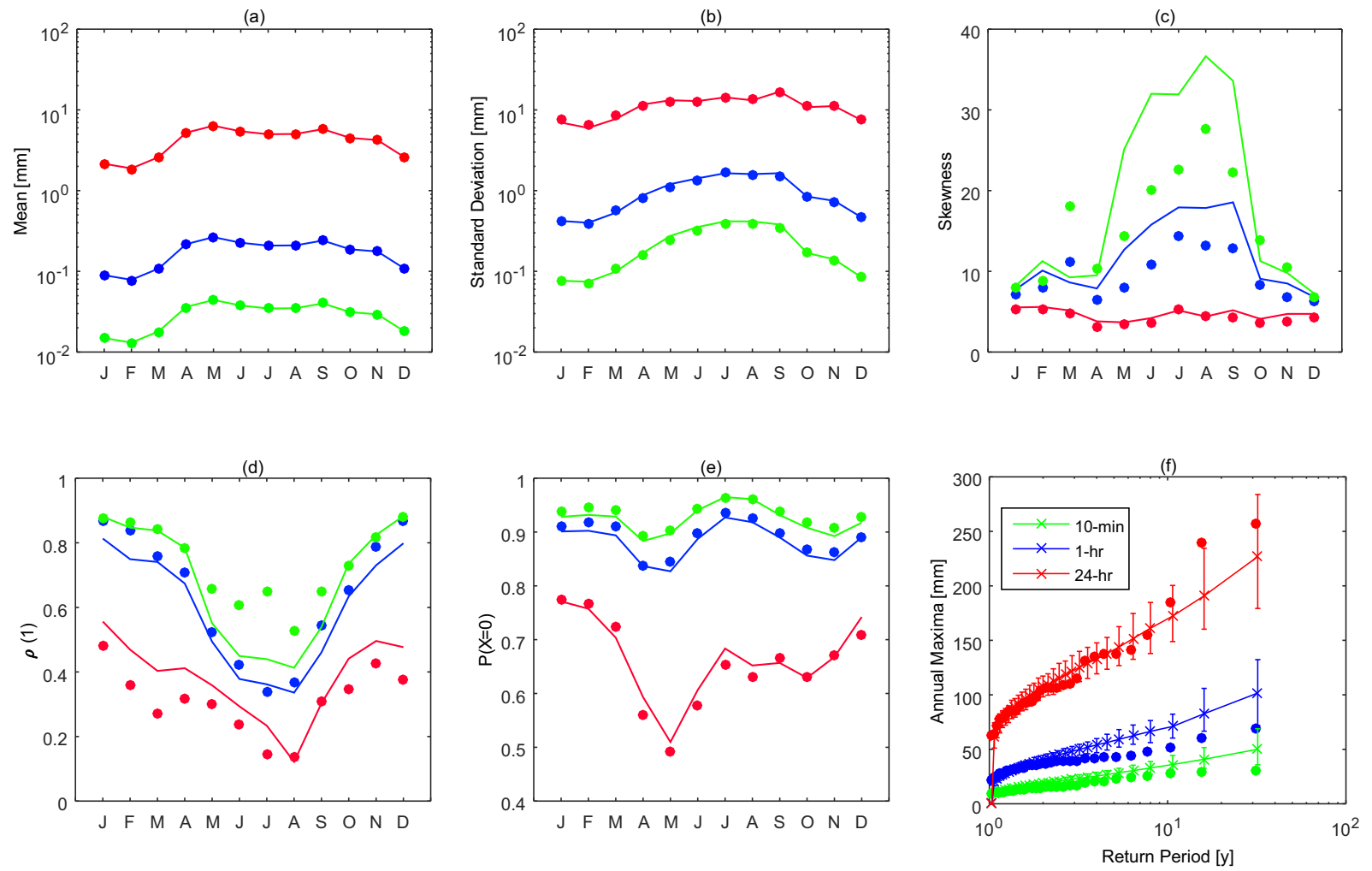

Figure 4. Simulated vs. observed monthly (a) mean precipitation, (b) standard deviation, (c) skewness, (d) lag-1 auto correlation, (e) probability of no rain, and (f) distribution of annual precipitation maxima for station Lugano at three temporal scales, with NSRP+MRCB. Markers represent observations and lines simulated values. In the simulated annual maxima distrubutions the mean and 10-90\% uncertainty bounds from $n=100$ simulations are shown.
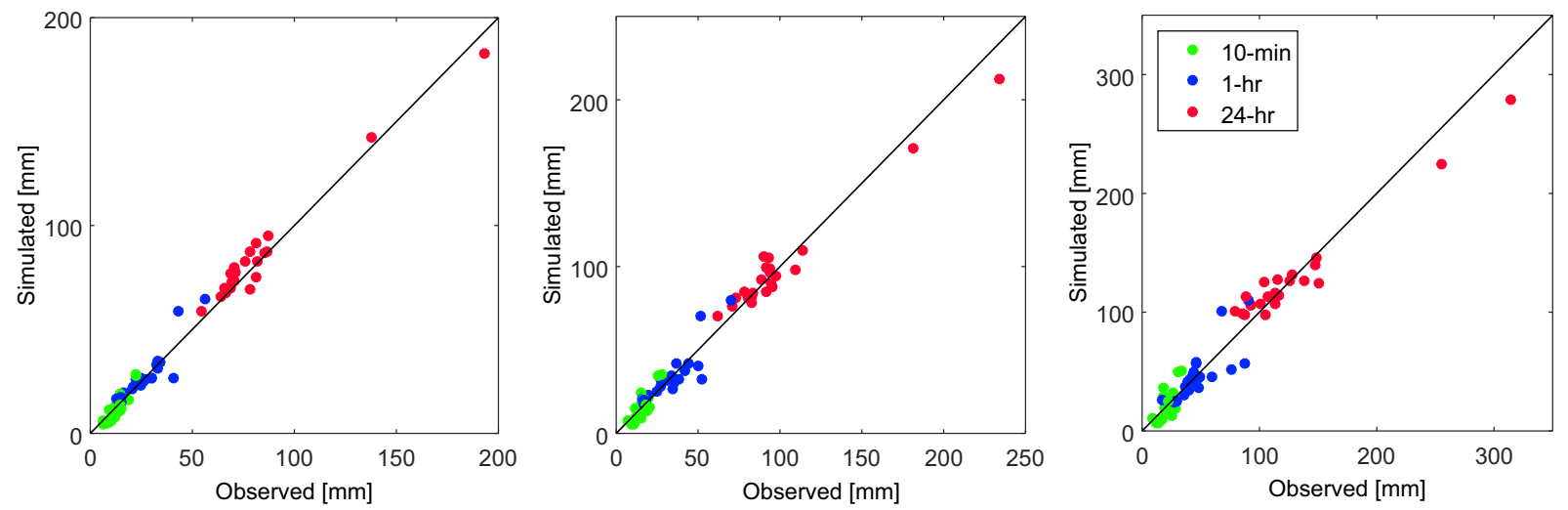

Figure 5. Observed versus simulated mean annual maximum precipitation depths for return periods RT = 5, 10 and 30 years (from left to right) for three different timescales (10 minutes, 1 hour and 1 day). Each marker is a different station. Simulated values are the means over $n=100$ realizations for all 22 studied stations. 
Hydrol. Earth Syst. Sci. Discuss., doi:10.5194/hess-2016-536, 2016

Manuscript under review for journal Hydrol. Earth Syst. Sci.

Published: 17 October 2016

(c) Author(s) 2016. CC-BY 3.0 License.

(c) (1)
Hydrology and Earth System Sciences

Discussions
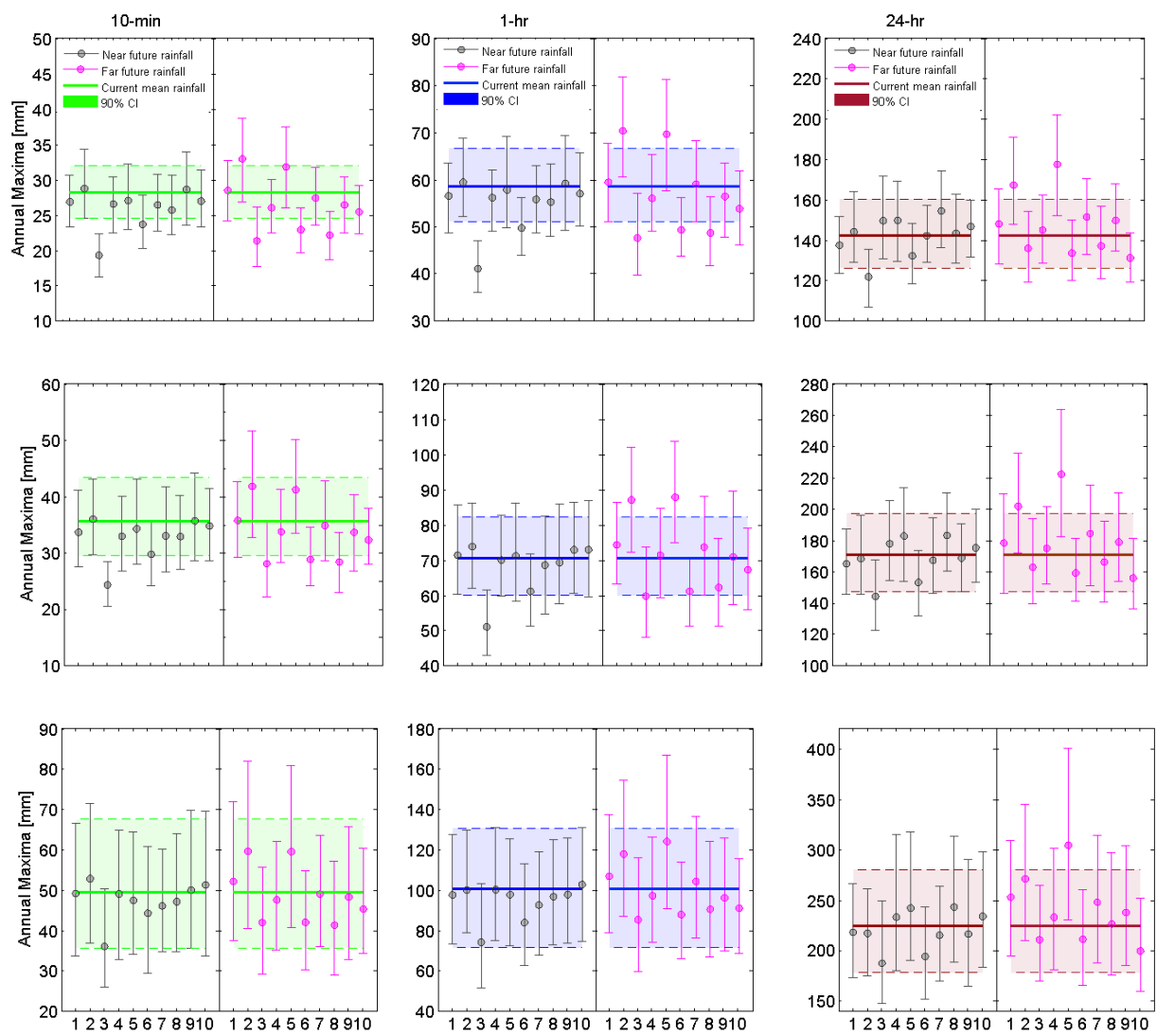

Figure 6. Boxplots of annual maximum precipitation depths ( $\mathrm{mm}$ ) for return periods $\mathrm{RT}=5,10$ and 30 years (from top to bottom) for the three different time scales (10-min, 1-hr and 24-hr, from left to right) for the near future and far future runs by 10 GCM-RCMs model runs ( $n=100$ realizations each). The black line with 10-90\% confidence bounds (dashed lines) gives the simulated mean for the current climate also from $n=100$ realizations. Example is for station Lugano. 
Hydrol. Earth Syst. Sci. Discuss., doi:10.5194/hess-2016-536, 2016

Manuscript under review for journal Hydrol. Earth Syst. Sci.

Published: 17 October 2016

(c) Author(s) 2016. CC-BY 3.0 License.
Hydrology and

Discussions

(c) $($ i)

(a) 10-min

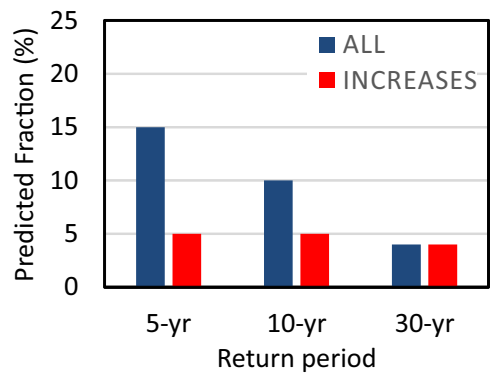

(b) 1-hr

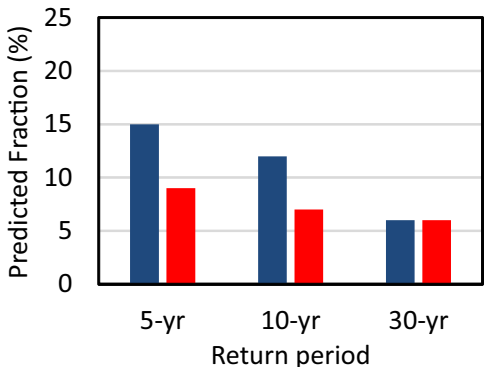

(c) $24-\mathrm{hr}$

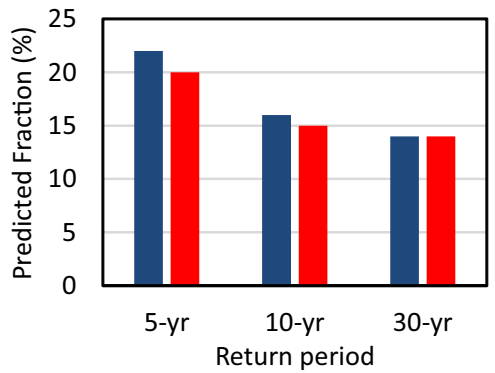

Figure 7. The predicted fraction of mean extremes for near future climate change simulations lying outside of the 10-90\% uncertainty bounds of the current climate for (a) 10-min, (b) 1-hr, and (c) 24-hr time resolutions and all three studied return periods. The fraction is computed in \% out of all 10 model runs and 22 stations, i.e. 220 outcomes. Shown are all changes outside of the uncertainty bounds (blue) and only those that predict an increase in the future climate (red). 